\title{
IMPLEMENTASI METODE WEIGHTED PRODUCT PADA SISTEM PENDUKUNG KEPUTUSAN PENERIMA BEASISWA BIDIKMISI UNIVERSITAS MATARAM
}

\author{
(Implementation Of Weighted Product Method In The Decision Support System Of \\ Recipients In Bidikmisi Scholarship Of Mataram)
}

Faraz Wahyudi, Moh. Ali Albar, Royana Afwani

Program Studi Teknik Informatika, Fakultas Teknik, Universitas Mataram

JI. Majapahit 62, Mataram, Lombok NTB, INDONESIA

Email: farazw45@gmail.com, [mohalialbar, royana]@unram.ac.id

\begin{abstract}
The awarding of scholarships is a work program that exists in every university or college. Bidikmisi is an education cost assistance program provided by the government through the Directorate General of Higher Education. In determining the students who take Bidikmisi scholarship, the University still uses the manual method by checking the student data one by one in Microsoft Excel by the Student Welfare Subdivision and the results of the data selection are sorted by their respective faculties or study programs. To assist in the selection process, a decision support system needs to be built, so that it can be considered in making decisions. In this decision support system using 10 criteria, among others: father's income, mother's income, number of dependents, home ownership, land area, building area, distance of the city center, bathing, washing, electricity and water sources. In this decision support system the calculation uses the weighted product method. The weighted productive method is used because this method is more able to provide weight values in each criterion, then ranking of the largest to the smallest from the calculation of the final value. In the development of this system, using the PHP programming language and database used mysql using the Codeigniter framework.
\end{abstract}

Keywords: Weighted Product, Bidikmisi Scholarship, Decision Support System, Codeigniter framework, mysql, PHP

\section{Pendahuluan}

Beasiswa adalah pemberian berupa bantuan keuangan yang diberikan kepada perorangan, mahasiswa, atau pelajar yang digunakan demi keberlangsungan pendidikan yang ditempuh. Beasiswa dapat diberikan oleh lembaga pemerintah, perusahaan,yayasan atau instansi-instansi yang lain. Salah satunya beasiswa yang terdapat di perguruan tinggi yaitu bidikmisi. Program beasiswa bidikmisi adalah program bantuan biaya pendidikan bagi calon mahasiswa tidak mampu secara ekonomi dan memiliki potensi akademik baik untuk menempuh pendidikan di perguruan tinggi [1].

Untuk mendapatkan beasiswa bidikmisi mahasiswa harus memenuhi persyaratan dan kriteriakriteria yang telah ditetapkan oleh Ristekdikti selaku penyelenggara beasiswa bidikmisi. Dalam melakukan penetapan mahasiswa peserta beasiswa bidikmisi pihak Universitas masih menggunakan cara manual yaitu dengan cara melakukan pengecekan kembali data mahasiswa satu persatu di Microsoft excel dengan cara mengurutkan data berdasarkan fakultas atau prodi oleh Subbagian Kesejahteraan Mahasiswa dan hasil seleksi selanjutnya akan diputusakan dalam rapat yang diadakan diruangan wakil rektor III. Kriteria yang menjadi acuan dalam menentukan mahasiswa penerima beasiswa bidikmisi antara lain penghasilan ortu, jumlah tanggungan, kepemilikan rumah, luas tanah, luas bangunan, mandi cuci kakus, sumber air, sumber listrik dan jarak pusat kota. Sehingga dapat memakan waktu cukup lama. Oleh karena itu, diperlukan suatu sistem pendukung keputusan untuk meminimalisir waktu seleksi serta dapat dijadikan dalam pengambian keputusan.

Sistem Pendukung Keputusan (SPK) adalah bagian dari sistem informasi berbasis komputer termasuk sistem berbasis pengetahuan atau menajemen pengetahuan yang dipakai untuk mendukung pengambilan keputusan dalam suatu organisasi atau perusahaan [1]. Dalam sistem pendukung keputusan terdapat beberapa metode seperti SAW (Simple Additive Weighting), WP (Weighted Product), AHP (Analytic Hierarchy Process), ELECTRE (Elimination and Choice Expressing Reality), TOPSIS (Technique for Order by Similarity to Ideal Solution), Fuzzy dan lain-lain [2]. Pada penelitian yang mengukur performa SAW dan 
Weighted Product yang dilakukan oleh Dewi Kusmawati pada tahun 2015 menyimpulkan bahwa penggunaan SAW dan WP sangat potensial untuk SPK pemberian beasiswa [3]. Metode yang digunakan dalam sistem pendukung keputusan ini adalah metode weighted product. Metode weighted product ini di pilih karena metode tersebut menentukan nilai bobot untuk setiap atribut, kemudian dilanjutkan dengan proses pemeringkatan yang akan menyeleksi alternatif terbaik dari sejumlah alternatif, dalam hal ini alternatif yang dimaksud adalah mahasiswa yang berhak menerima beasiswa berdasarkan kriteria-kriteria yang di tentukan [4]. Pada peneltian sistem seleksi pengangkatan karyawan tetap metode WP (Weighted Product) terbukti lebih efisien dengan rata-rata waktu yang dibutuhkan sebesar 1.6408 detik, jika dibandingkan dengan metode SAW (Simple Additive Weighting) yang membutuhkan waktu rata-rata 6.5822 detik. Metode WP (Weighted Product) terbukti lebih efisien dengan rata-rata selisih waktu sebesar 4.9414 detik dalam hal waktu yang dibutuhkan untuk melakukan perhitungan [5].

Dari permasalahan yang telah dipaparkan diatas peneliti membuat Sistem Pendukung Keputusan dengan judul penelitian "Implementasi metode Weighted Product pada Sistem Pendukung Keputusan Penerima Beasiswa Bidikmisi Universitas Mataram" yang diharapkan dapat membantu dalam penentuan mahasiswa penerima beasiswa bidikmisi secara cepat untuk menghasilkan output yang dapat digunakan sebagai sarana penunjang keputusan.

\section{TINJAUAN PUSTAKA DAN DASAR TEORI}

\subsection{Tinjauan Pustaka}

Berdasarkan penelitian tentang "Penerapan Metode PROMETHEE Dalam Sistem Penunjang Keputusan Penentuan Penerima Beasiswa Bidik Misi Universitas Halu Oleo". Dalam pembangunan sistem ini, peneliti menggunakan bahasa pemograman java netbeans dan database yang digunakan mysql. Dalam melakukan perhitungan menggunakan tujuh kriteria antara lain Pekerjaan ayah, pekerjaan ibu, penghasilan orangtua, tanggungan orang tua, kepemilikan rumah, luas tanah dan luas rumah. Dari hasil perbandingan antara hasil penentuan penerima beasiswa bidikmisi berdasarkan sistem menggunakan metode PROMETHEE dengan hasil penentuan berdasarkan keputusan UHO terhadap 24 data uji maka diperoleh 23 data calon penerima beasiswa Bidik Misi yang berhak menerima beasiswa tersebut [6].

Pada penelitian tentang "Implementasi Metode Weighted Product Menentukan Beasiswa Bidik Misi
STMIK Pringsewu" dalam perhitungannya menggunakan lima kriteria yaitu indeks prestasi semester, penghasilan orang tua, jumlah tanggungan, pengabdian pkm, dan kelayakan rumah. Dalam penelitian ini menyimpulkan Sistem Pendukung Keputusan untuk menentukan penerimaan beasiswa Bidik Misi pada STMIK Pringsewu dapat membantu dan mempermudah Perguruan Tinggi dalam menentukan mahasiswa yang layak atau tidaknya mendapatkan beasiswa berdasarkan kriteria-kriteria yang telah ditentukan [7].

Penelitian tentang "Sistem Pendukung Keputusan Penentuan Penerimaan Mahasiswa Baru Jalur Bidikmisi Menggunakan Metode Topsis (Studi Kasus : Politeknik Negeri Malang) ". Pengujian dilakukan dengan membandingkan data riil penerima yang telah dinyatakan diterima melalui jalur bidikmisi sebanyak 250 mahasiswa, kemudian dibandingkan dengan hasil perhitungan sistem sebanyak 250 mahasiswa. Hasil pengujian dari perhitungan sistem terdapat 108 mahasiswa yang seharusnya tidak diterima tapi diterima di data riil penerima bidikmisi tahun 2016 .. Dalam penelitian ini menyimpulkan sistem ini telah membantu tim seleksi dalam mengurangi kesalahan atau ketidak tepatan proses penilaian. Hasil pengujian dapat menyaring $56,8 \%$ dari data riil penerima bidikmisi atau 108 mahasiswa yang tidak diterima di bidikmisi [2].

Penelitian tentang " Sistem Pendukung Keputusan Penerimaan Beasiswa Bidik Misi di POLIBAN Dengan Metode SAW Berbasis Web" dalam perhitungannya menggunakan kriteria-kriteria yaitu penghasilan orang tua, jumlah tanggungan, nilai rata-rata raport semester empat dan lima, bukti rekening listrik dan bukti pembayaran PBB. Dalam penelitian ini dihasilkan kesimpulan sistem pendukung keputusan penerimaan beasiswa bidik misi ini dapat dengan baik melakukan perangkingan [1].

\subsection{Dasar Teori}

Berikut teori-teori yang mendasari dalam pembuatan sistem dalam pembuatan dalam pembuatan sistem pendukung :

\subsubsection{Metode Weighted Product}

Weighted Product (WP) adalah keputusan analisis multi-kriteria dan merupakan metode pengambilan keputusan multi kriteria. Seperti semua metodemetode lainanya, WP adalah himpunan dari alternatif keputusan yang dijelaskan dalam istilah beberapa kriteria. Metode perkalian atau metode WP ini berbeda dengan metode SAW dalam perlakuan awal terhadap hasil penilaian atribut keputusan. Dalam metode WP tidak diperlukan manipulasi matriks 
karena metode ini mengalikan hasil penilaian setiap atribut. Hasil perkalian tersebut belum dibandingkan (dibagi) dengan nilai standar, dalam hal ini alternatif ideal sering digunakan sebagai nilai standar bobot, bobot untuk atribut manfaat berfungsi sebagai pangkat positif dalam proses perkalian antar atribut, sementara bobot berfungsi sebagai pangkat negatif [8]. Terdapat variabel cost dan benefit berguna untuk menentukan kriteria dan berpengaruh dalam pengambilan keputusan. Kriteria yang termasuk benefit jika nilai terbesar adalah yang terbaik (bobot bernilai negatif), sedangkan cost jika nilai terkecil adalah yang terbaik (bobot bernilai positif).

Metode Weighted Product menggunakan perkalian untuk menghubungkan rating atribut, dimana rating setiap atribut harus dipangkatkan terlebih dahulu dengan bobot atribut yang bersangkutan. Proses ini sama halnya dengan proses normalisasi [8].

Proses normalisasi bobot kriteria (W), $\Sigma \mathrm{W}=1$ adalah:

$$
W_{j}=\frac{W_{j}}{\sum W_{j}}
$$

Keterangan:

Wj: Bobot kriteria

$\mathrm{w}_{\mathrm{j}}:$ w indeks ke-j

$\Sigma$ Wj: Penjumlahan bobot kriteria

Menghitung Vektor $S$

$$
S_{i}=\prod_{j=1}^{n} X_{i j}{ }^{W_{j}}
$$

Keterangan:

$S_{i}:$ nilai dari setiap altenatif

$X_{i j}$ : menyatakan nilai/skor kriteria

$\mathrm{W}_{\mathrm{j}}$ : bobot setiap kriteria

i: menyatakan alternatif

$\mathrm{j}$ : menyatakan kriteria

$\mathrm{n}$ : menyatakan banyaknya kriteria

Menghitung Vektor V:

$$
V_{i}=\frac{\prod_{j=1}^{n} X_{i j}{ }^{W_{j}}}{\prod_{j=1}^{n}\left(X_{i j}{ }^{*}\right)}
$$

Keteragan:

V: menyatakan alternatif yang dianalogikan sebagai vektor $\mathrm{V}$

$\mathrm{X}_{\mathrm{ij}}$ : menyatakan nilai/skor kriteria

$\mathrm{W}_{\mathrm{j}}$ : bobot setiap kriteria

i: menyatakan alternatif

j: menyatakan kriteria

$\mathrm{n}$ : menyatakan banyaknya kriteria.

\subsubsection{Sistem Pendukung Keputusan}

Sistem Pendukung Keputusan (SPK) atau Decision Support System (DSS) adalah sebuah sistem yang mampu memberikan kemampuan pemecahan masalah maupun kemampuan pengkomunikasian untuk masalah dengan kondisi semi terstruktur dan tak terstruktur. Sistem ini digunakan untuk membantu pengambilan keputusan dalam situasi semi terstruktur dan situasi yang tidak terstruktur, dimana tak seorangpun tahu secara pasti bagaimana keputusan seharusnya dibuat. SPK bertujuan untuk menyediakan informasi, membimbing, memberikan prediksi serta mengarahkan kepada pengguna informasi agar dapat melakukan pengambilan keputusan dengan lebih baik [9].

\section{Metode Penelitian}

\subsection{Metodologi Penelitian}

Pada penelitian ini akan membahas tentang merancang dan membangun sistem yang berupa sistem pendukung keputusan penerima beasiswa bidikmisi. Sistem ini dapat membantu pihak terkait dalam menentukan mahasiswa yang layak mendapatkan beasiswa bidikmisi secara objektif di Universitas Mataram. Prosedur pelaksanaan penelitian dapat dilihat pada Gambar 1.

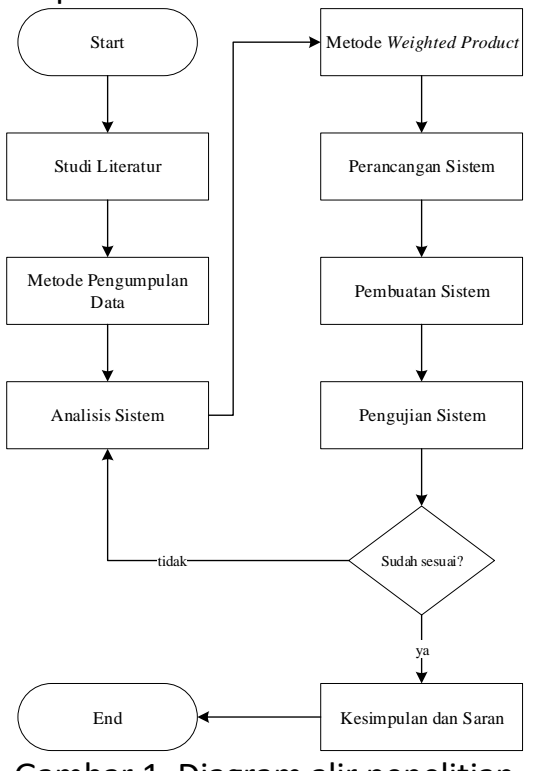

Gambar 1. Diagram alir penelitian

\subsection{Studi Literatur}

Studi literatur berfungsi untuk mengumpulkan dan mendalami teori teori yang berkaitan dengan perancangan dan pembuatan sistem pendukung keputusan penerima beasiswa bidikmisi. Adapun literatur yang digunakan berupa penelitian terdahulu dan dasar-dasar teori yang terkait. 


\subsection{Metode Pengumpulan Data}

Adapun metode pengumpulan data sebagai berikut:

a. Observasi

Penulis melakukan pengamatan langsung objek penelitian berupa data mahasiswa penerima beasiswa bidikmisi Universitas Mataram. Data yang didapat berupa data mentah dan data daftar penerima beasiswa bidikmisi Universitas Mataram tahun 2018.

b. Wawancara

Penulis melakukan pendekatan komunikasi yang berhubungan langsung dengan bapak Masri Rakasiwi di Kasubbag Kesejahteraan Mahasiswa Universitas Mataram selaku admin yang mengelola data mahasiswa peserta bidikmisi. Hasil wawancara yang didapat berupa alur kerja atau standar operasional proses seleksi calon penerima beasiswa bidikmisi Universitas Mataram.

\subsection{Analisis Sistem}

Analisis sistem merupakan penjabaran dari suatu sistem informasi yang utuh ke dalam berbagai macam bagian komponennya dengan maksud agar dapat mengidentifikasi atau mengevaluasi berbagai macam masalah maupun hambatan yang akan timbul pada sistem sehingga nantinya dapat dilakukan penanggulangan, perbaikan atau juga pengembangan [10].

\subsubsection{Analisis Sistem Yang Sedang Berjalan}

Analisis sistem berjalan bertujuan untuk mengetahui alur kerja dari sistem yang telah ada. Dari alur kerja yang telah ada dan ditemukan masalah yang telah dijelaskan pada latar belakang, maka masalah tersebut dijadikan acuan untuk membuat perancangan sistem yang baru. Sistem yang digunakan dalam menentukan mahasiswa yang layak mendapat beasiswa bidikmisi masih bersifat manual dengan cara melakukan pengecekan data mahasiswa satu persatu pada Microsoft excel serta melakukan rapat atau diskusi yang bertempat di ruangan wakil rektor III Universitas Mataram.

\subsubsection{Analisis Prosedur Yang Sedang Berjalan}

Analisis prosedur yang berjalan bertujuan untuk mengetahui prosedur kerja yang terjadi di lapangan. Hasil dari analisis tersebut berupa kronologi kejadian secara langsung dari urutan kegiatan yang dilakukan khususnya berhubungan dengan mengolah data. Dapat dilihat pada Gambar 2 sebagai berikut:

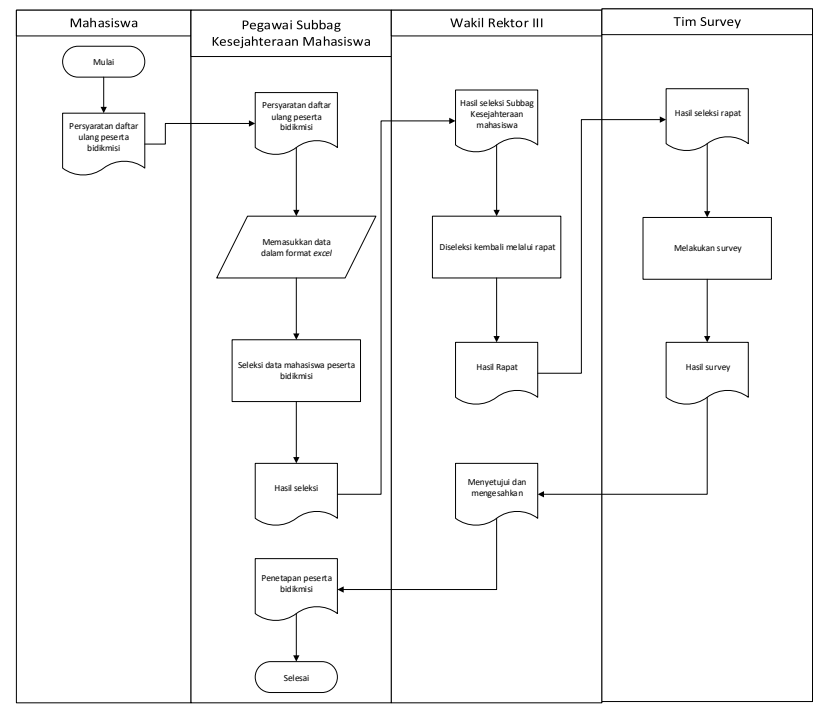

Gambar 2. Flowmap sistem yang sedang berjalan

3.4.3. Analisis Prosedur Sistem Yang Akan Dibangun

Analisa sistem yang akan di bangun bertujuan untuk mengetahui dan mendeskripsikan cara kerja dan prosedur kerja dari system. Dapat dilihat pada Gambar 3, sebagai berikut :

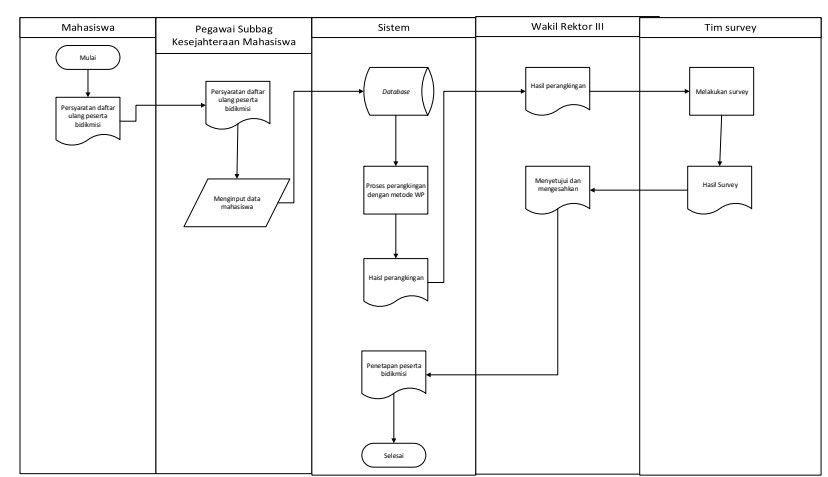

Gambar 3. Flowmap sistem yang akan dibangun

\subsubsection{Analisis Kebutuhan Sistem}

Kebutuhan pembuatan sistem pendukung keputusan penerima baesiswa bidikmisi membutuhkan beberapa alat dan bahan yang terdiri dari perangkat keras (hardware) dan perangkat lunak (software).

Perangkat keras yang dibutuhkan untuk membuat sistem berupa laptop yang akan digunakan sebagai media pembangunan sistem dan untuk uji coba sistem.

Perangkat lunak yang dibutuhkan untuk membuat sistem pendukung keputusan yaitu: 
1. OS (operating system), pada pembuatan aplikasi digunakan Windows 10 64-bit sebagai media untuk menjalankan software yang lain yang akan digunakan untuk membuat sistem.

2. Visual Studio code merupakan text editor yang akan digunakan untuk membuat code program dari aplikasi yang akan dibuat pada tugas akhir ini.

3. Menggunakan PHP sebagai bahasa pemrogramannya

4. Codelgniter digunakan sebagai framework pembuatan aplikasi berupa website yang akan mempermudah dalam pembangunan aplikasi.

5. XAMPP merupakan software web server apache yang didalamnya terdapat MySQL yang akan digunakan sebagai server dalam pembuatan aplikasi dan digunakan untuk mengelola database yang dibutuhkan aplikasi.

6. Microsoft office 2016 digunakan untuk penyusunan laporan.

Bahan yang dibutuhkan untuk membuat sistem berupa data mahasiswa penerima beasiswa bidikmisi tahun 2018.

\subsection{Metode Weighted Product}

Weighted Product (WP) adalah keputusan analisis multi-kriteria dan merupakan metode pengambilan keputusan multi kriteria. Berikut alur perhitungan dari metode weighted product.

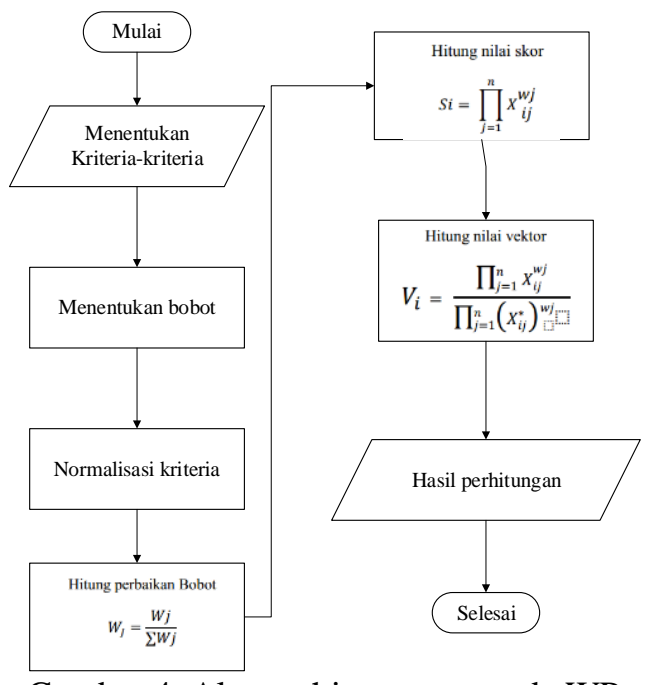

\subsubsection{Langkah-Langkah Perhitungan}

\section{Menentukan Kriteria}

Adapun Kriteria-kriteria dan bobot yang digunakan dapat dilihat pada tabel 1 dan pada tabel 2 digunakan sebagai acuan dalam pemberian bobot pada setiap kriteria.
TABEL I. TABEL KRITERIA.

\begin{tabular}{|l|l|l|}
\hline No & Kriteria & Bobot \\
\hline 1 & Penghasilan Ayah & 5 \\
\hline 2 & Penghasilan Ibu & 5 \\
\hline 3 & Jumlah Tanggugan & 4 \\
\hline 4 & Kepemilikan Rumah & 3 \\
\hline 5 & Luas Tanah & 3 \\
\hline 6 & Luas Bangunan & 3 \\
\hline 7 & Jarak Pusat Kota & 3 \\
\hline 8 & Mandi Cuci Kakus & 2 \\
\hline 9 & Sumber Air & 1 \\
\hline 10 & Sumber Listrik & 1 \\
\hline
\end{tabular}

\begin{tabular}{|l|l|}
\hline \multicolumn{1}{|c|}{ Kriteria Penilaian } & Nilai \\
\hline Sangat rendah & 1 \\
\hline Rendah & 2 \\
\hline Sedang & 3 \\
\hline Tinggi & 4 \\
\hline Sangat tinggi & 5 \\
\hline
\end{tabular}

TABEL II. TINGKAT BOBOT KRITERIA

Setelah pemberian bobot selesai pada masingmasing kriteria dilanjutkan dengan menentukan subkriteria dari masing-masing kriteria beserta nilainya, dapat dilihat pada tabel 3

TABEL III. TABEL SUBKRITERIA

\begin{tabular}{|c|c|c|c|c|}
\hline No & Kriteria & Sub kriteria & $\begin{array}{l}\text { Sk } \\
\text { or }\end{array}$ & $\begin{array}{l}\text { Keteran } \\
\text { gan }\end{array}$ \\
\hline \multirow[t]{5}{*}{1} & \multirow{5}{*}{$\begin{array}{l}\text { Penghas } \\
\text { ilan } \\
\text { Ayah }\end{array}$} & $>\operatorname{Rp} 2.000 .000$ & 1 & \multirow[t]{5}{*}{ Cost } \\
\hline & & $\begin{array}{l}>\mathrm{Rp} \\
1.500 .000- \\
2.000 .000\end{array}$ & 2 & \\
\hline & & $\begin{array}{l}>\mathrm{Rp} \\
1.000 .000- \\
1.500 .000\end{array}$ & 3 & \\
\hline & & $\begin{array}{l}>\operatorname{Rp} 500.000- \\
1.000 .000\end{array}$ & 4 & \\
\hline & & $<=\operatorname{Rp} 500.000$ & 5 & \\
\hline \multirow[t]{5}{*}{2} & \multirow{5}{*}{$\begin{array}{l}\text { Penghas } \\
\text { ilan Ibu }\end{array}$} & $>\operatorname{Rp} 2.000 .000$ & 1 & \multirow[t]{5}{*}{ Cost } \\
\hline & & $\begin{array}{l}>\mathrm{Rp} \\
1.500 .000- \\
2.000 .000\end{array}$ & 2 & \\
\hline & & $\begin{array}{l}>\mathrm{Rp} \\
1.000 .000- \\
1.500 .000\end{array}$ & 3 & \\
\hline & & $\begin{array}{l}>\operatorname{Rp} 500.000- \\
1.000 .000\end{array}$ & 4 & \\
\hline & & $<=\operatorname{Rp} 500.000$ & 5 & \\
\hline 3 & & 1-2 orang & 1 & Benefit \\
\hline
\end{tabular}




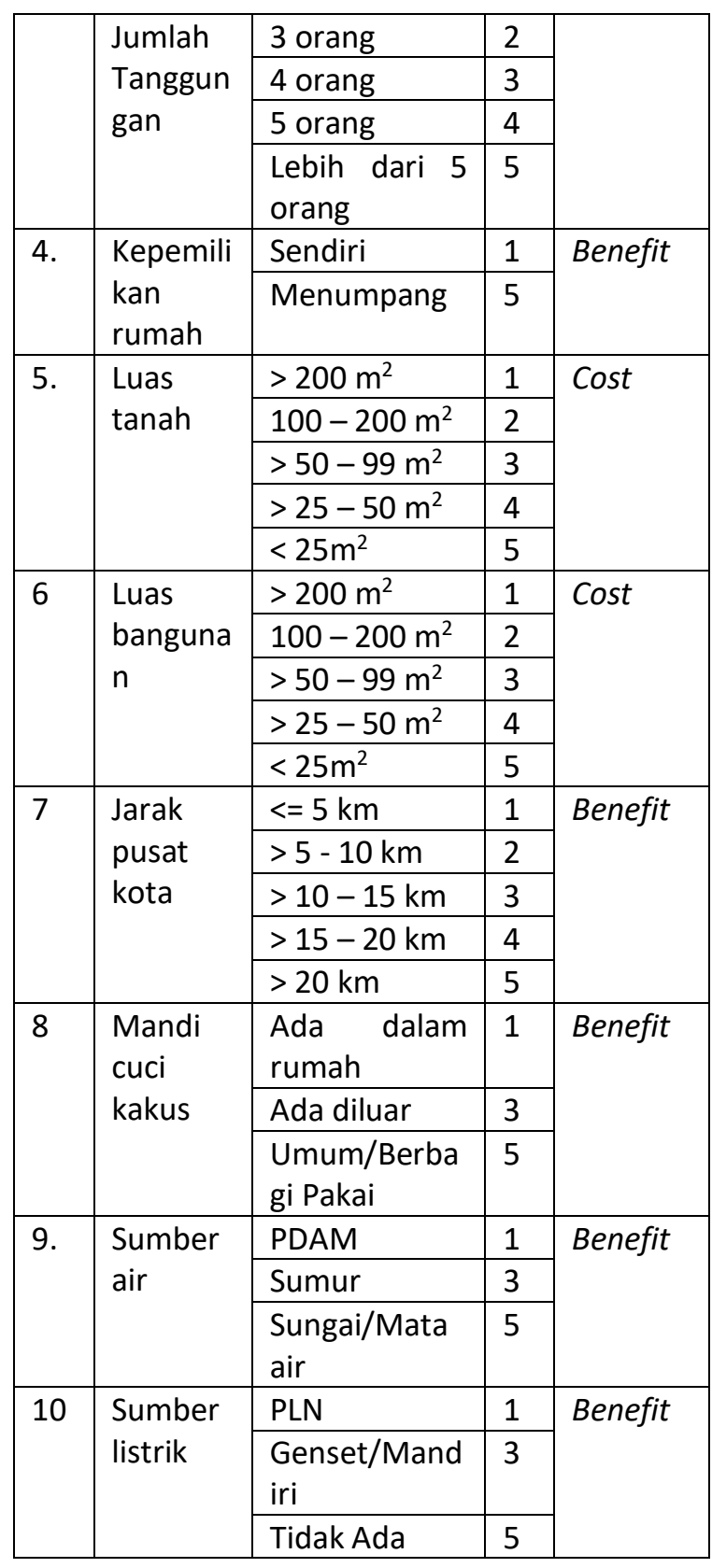

Keterangan :

Benefit = jika nilai terbesar adalah terbaik (bobot bernilai negatif).

Cost = jika nilai terkecil adalah terbaik (bobot bernilai positif).

2. Menghitung perbaikan bobot

Proses normalisasi bobot kriteria (W), $\Sigma W=1$ adalah:

$W_{j}=\frac{W_{j}}{\sum W_{j}}$

Keterangan:

Wj: Bobot kriteria

$\mathrm{w}_{\mathrm{j}}$ : $\mathrm{w}$ indeks ke-j

$\Sigma \mathrm{Wj}$ : Penjumlahan bobot kriteria
Proses Perhitungan normalisasi bobot dengan rumus diatas:

$$
\begin{aligned}
& W_{1}=\frac{5}{5+5+4+3+3+3+3+2+1+1}=\frac{5}{30}=0,167 \\
& W_{2}=\frac{5}{5+5+4+3+3+3+3+2+1+1}=\frac{5}{30}=0,167 \\
& W_{3}=\frac{4}{5+5+4+3+3+3+3+2+1+1}=\frac{4}{30}=0,133 \\
& W_{4}=\frac{3}{5+5+4+3+3+3+3+2+1+1}=\frac{3}{30}=0,100 \\
& W_{5}=\frac{3}{5+5+4+3+3+3+3+2+1+1}=\frac{3}{30}=0,100 \\
& W_{6}=\frac{3}{5+5+4+3+3+3+3+2+1+1}=\frac{3}{30}=0,100 \\
& W_{7}=\frac{3}{5+5+4+3+3+3+3+2+1+1}=\frac{3}{30}=0,100 \\
& W_{8}=\frac{2}{5+5+4+3+3+3+3+2+1+1}=\frac{2}{30}=0,067 \\
& W_{9}=\frac{1}{5+5+4+3+3+3+3+2+1+1}=\frac{1}{30}=0,033 \\
& W_{10}=\frac{1}{5+5+4+3+3+3+3+2+1+1}=\frac{1}{30}=0,033
\end{aligned}
$$

Setelah mendapatkan hasil perhitungan diatas dapat dilihat normalisasi bobot pada tabel 4 .

TABEL IV. BOBOT DAN KRITERIA SETELAH NORMALISASI.

\begin{tabular}{|l|l|l|l|}
\hline No & Kriteria & $\begin{array}{l}\text { Bobot } \\
\text { (Sebelum } \\
\text { ) }\end{array}$ & $\begin{array}{l}\text { Bobot } \\
\text { (Sesudah) }\end{array}$ \\
\hline 1 & $\begin{array}{l}\text { Penghasilan } \\
\text { Ayah }\end{array}$ & 5 & 0,167 \\
\hline 2 & $\begin{array}{l}\text { Penghasilan } \\
\text { Ibu }\end{array}$ & 5 & 0,167 \\
\hline 3 & $\begin{array}{l}\text { Jumlah } \\
\text { Tanggugan }\end{array}$ & 4 & 0,133 \\
\hline 4 & $\begin{array}{l}\text { Kepemilikan } \\
\text { Rumah }\end{array}$ & 3 & 0,100 \\
\hline 5 & Luas Tanah & 3 & 0,100 \\
\hline 6 & $\begin{array}{l}\text { Luas } \\
\text { Bangunan }\end{array}$ & 3 & 0,100 \\
\hline 7 & $\begin{array}{l}\text { Jarak Pusat } \\
\text { Kota }\end{array}$ & 3 & 0,100 \\
\hline 8 & $\begin{array}{l}\text { Mandi Cuci } \\
\text { Kakus }\end{array}$ & 2 & 0,067 \\
\hline 9 & Sumber Air & 1 & 0,033 \\
\hline 10 & $\begin{array}{l}\text { Sumber } \\
\text { Listrik }\end{array}$ & 1 & 0,033 \\
\hline $5 \mathrm{~W}$ & & 30 & 1 \\
\hline
\end{tabular}

3. Menghitung nilai skor

Sebelum menghitung nilai skor terlebih dahulu data dikonversi sesuai dengan nilai atau skor pada tabel 3. Hasil konversi dapat dilihat pada tabel 5. 
TABEL V. TABEL KONVERSI NILAI DATA MAHASISWA.

\begin{tabular}{|l|l|l|l|l|l|l|l|l|l|l|}
\hline Alter & \multicolumn{10}{|c|}{ Kriteria } \\
\cline { 2 - 12 } natif & C & C & C & C & C & C & C & C & C & C \\
& 1 & 2 & 3 & 4 & 5 & 6 & 7 & 8 & 9 & 10 \\
\hline A1 & 5 & 5 & 1 & 1 & 5 & 1 & 5 & 3 & 3 & 1 \\
\hline A2 & 5 & 5 & 4 & 1 & 2 & 2 & 5 & 5 & 5 & 1 \\
\hline A3 & 5 & 5 & 2 & 1 & 4 & 2 & 1 & 1 & 3 & 1 \\
\hline A4 & 4 & 5 & 4 & 1 & 4 & 2 & 5 & 5 & 3 & 1 \\
\hline A5 & 5 & 5 & 2 & 1 & 1 & 1 & 5 & 3 & 5 & 1 \\
\hline
\end{tabular}

Keterangan :

A : alternatif (mahasiswa).

$C$ : Kriteria.

Setelah melakukan konversi nilai barulah dihitung nilai skor dengan rumus sebagai berikut :

$S_{i}=\prod_{j=1}^{n} X_{i j}{ }^{W_{j}}$

Keterangan:

$\mathrm{S}_{\mathrm{i}}$ : nilai dari setiap altenatif

$\mathrm{X}_{\mathrm{ij}}$ : menyatakan nilai/skor kriteria

$\mathrm{W}_{\mathrm{j}}$ : bobot setiap kriteria

i: menyatakan alternatif

j: menyatakan kriteria

$\mathrm{n}$ : menyatakan banyaknya kriteria

Berikut proses perhitungan menggunakan rumus diatas :

$S_{1}=\left(5^{0,167}\right)\left(5^{0,167}\right)\left(1^{-0,133}\right)\left(1^{-0,100}\right)\left(5^{0,100}\right)\left(1^{0,100}\right)\left(5^{-0,100}\right)$ $\left(3^{-0,067}\right)\left(3^{-0,033}\right)\left(1^{-0,033}\right)=1,533712$

$S_{2}=\left(5^{0,167}\right)\left(5^{0,167}\right)\left(4^{-0,133}\right)\left(1^{-0,100}\right)\left(2^{0,100}\right)\left(2^{0,100}\right)\left(5^{-0,100}\right)$ $\left(5^{-0,067}\right)\left(5^{-0,033}\right)\left(1^{-0,033}\right)=1,185206$

$\mathrm{S}_{3}=\left(5^{0,167}\right)\left(5^{0,167}\right)\left(2^{-0,133}\right)\left(1^{-0,100}\right)\left(4^{0,100}\right)\left(2^{0,100}\right)\left(1^{-0,100}\right)$

$\left(1^{-0,067}\right)\left(3^{-0,033}\right)\left(1^{-0,033}\right)=1,853459$

$\mathrm{S}_{4}=\left(4^{0,167}\right)\left(5^{0,167}\right)\left(4^{-0,133}\right)\left(1^{-0,100}\right)\left(4^{0,100}\right)\left(2^{0,100}\right)\left(5^{-0,100}\right)$

$\left(5^{-0,067}\right)\left(3^{-0,033}\right)\left(1^{-0,033}\right)=1,244612$

$S_{5}=\left(5^{0,167}\right)\left(5^{0,167}\right)\left(2^{-0,133}\right)\left(1^{-0,100}\right)\left(1^{0,100}\right)\left(1^{0,100}\right)\left(5^{-0,100}\right)$ $\left(3^{-0,067}\right)\left(3^{-0,033}\right)\left(1^{-0,033}\right)=1,190721$

4. Menghitung nilai vektor

Setelah menghitung nilai skor selanjutnya menghitung nilai vektor, dimana hasilnya digunakan sebagai hasil akhir. Berikut rumus yang digunkan untuk menghitung nilai vektor :

$$
V_{i}=\frac{\prod_{j=1}^{n} X_{i j}{ }^{W_{j}}}{\prod_{j=1}^{n}\left(X_{i j}{ }^{*}\right)}
$$

Keteragan:

$\mathrm{V}$ : menyatakan alternatif yang dianalogikan sebagai vektor $\mathrm{V}$
$\mathrm{X}_{\mathrm{ij}}$ : menyatakan nilai/skor kriteria

$\mathrm{W}_{\mathrm{j}}$ : bobot setiap kriteria

i: menyatakan alternatif

$\mathrm{j}$ : menyatakan kriteria

$\mathrm{n}$ : menyatakan banyaknya kriteria

Proses perhitungan nilai vektor sebagai berikut :

$$
\begin{aligned}
V_{1} & =\frac{1,533712}{1,533712+1,185206+1,853459+1,244612+1,190721}=\frac{1,533712}{7,00771} \\
& =0,218861
\end{aligned}
$$

$\begin{aligned} V_{2} & =\frac{1,185206}{1,533712+1,185206+1,853459+1,244612+1,190721}=\frac{1,185206}{7,00771} \\ & =0.169129\end{aligned}$

$V_{3}=\frac{1,853459}{1,533712+1,185206+1,853459+1,244612+1,190721}=\frac{1,853459}{7,00771}$ $=0.264489$

$\mathrm{V}_{4}=\frac{1,244612}{1,533712+1,185206+1,853459+1,244612+1,190721}=\frac{1,244612}{7,00771}$ $=0.177606$

$V_{5}=\frac{1,190721}{1,533712+1,185206+1,853459+1,244612+1,190721}=\frac{1,190721}{7,00771}$ $=0.169916$

Dari perhitungan yang telah dilakukan didapat bahwa $\mathrm{A} 3$ atau mahasiswa nomor 3 memliki nilai $\mathrm{V}$ tertingi sehingga A3 sangat direkomendasikan mendapat beasiswa untuk lebih jelas dapat dilihat pada tabel 6 .

TABEL VI. HASIL PERANGKINGAN WP.

\begin{tabular}{|l|l|l|}
\hline Rangking WP & Alternatif & Nilai V \\
\hline 1 & A3 & 0.264489 \\
\hline 2 & A1 & 0.218861 \\
\hline 3 & A4 & 0.177606 \\
\hline 4 & A5 & 0.169916 \\
\hline 5 & A2 & 0.169129 \\
\hline
\end{tabular}

3.6. Perancangan Sistem

Berikut perancangan sistem yang akan dibangun :

\subsubsection{Usecase Diagram}

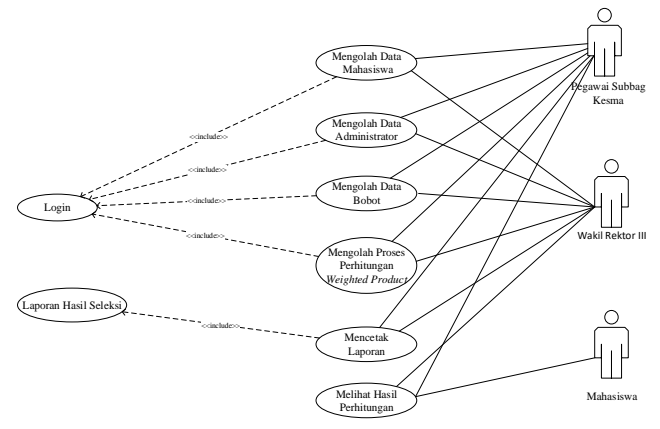

Gambar 5.Usecase diagram 


\subsubsection{Class Diagram}

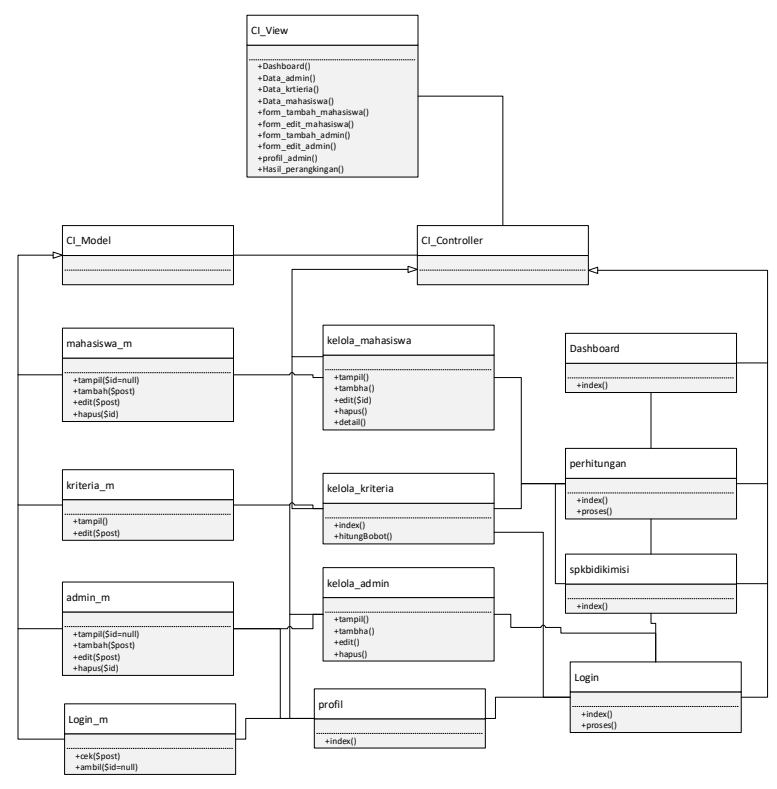

Gambar 6.Class diagram

Sistem yang dibangun menggunakan metode analisa dan perancangan berorientasi objek dan menggunakan pola arsitektur Model View Controller (MVC), sehingga dilakukan perancangan kelas - kelas yang ada pada sistem yang terdiri dari kelas Controller dan Model. Pada kelas Controller terdapat kelas kelola_kriteria, kelola_mahasiswa, kelola_admin, perhitungan, Dashboard, spkbidimisi, Login dan profil. Sedangkan pada Model terdapat kelas Login_m, admin_m, mahasiswa_m, dan kritria_m.

\subsubsection{Entity Relatinship Diagram (ERD)}

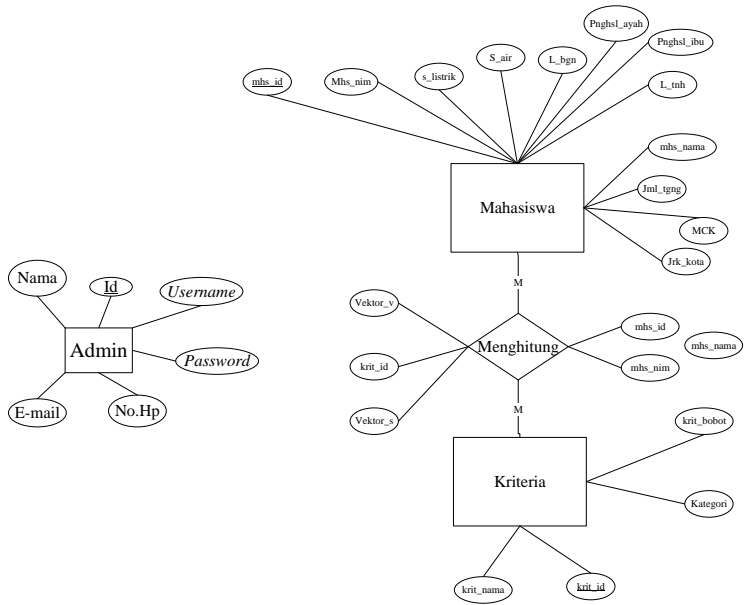

Gambar 7. Entity relationship diagram

Gambar 7 merupakan entinity relationship diagram yang terdiri dari tiga entitas yaitu Mahasiswa, Kriteria, dan Admin, serta terdapat tabel relasi yaitu menghitung.

\subsubsection{Desain Tampilan Sistem}

Berikut merupakan rancangan interface dari sistem yang akan dibangun:

1. Halaman login

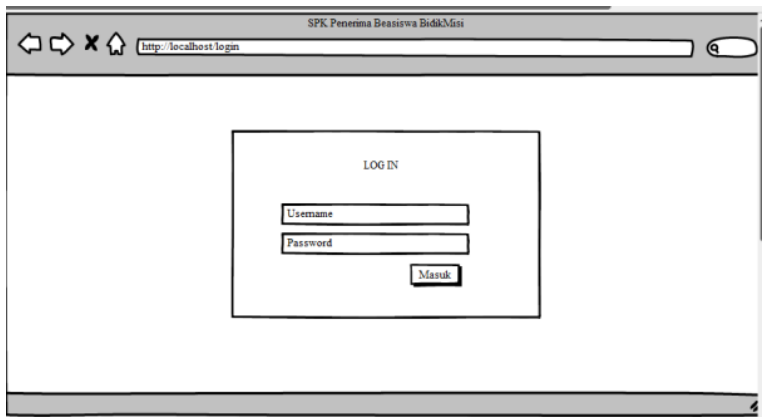

Gambar 8. Halaman login

2. Halaman kelola data

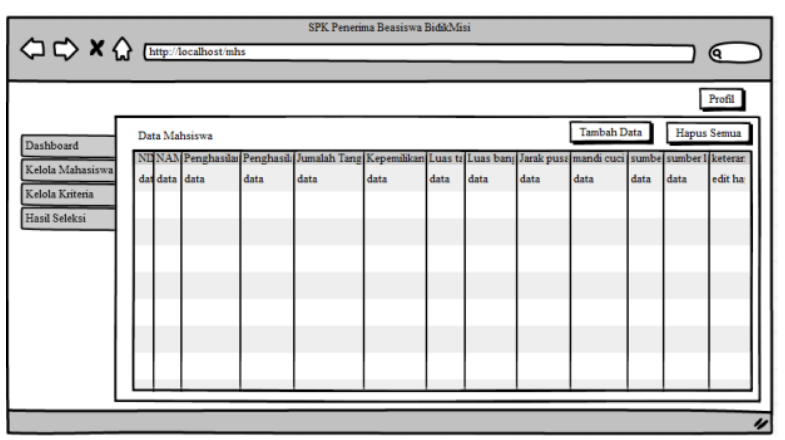

Gambar 9. Halaman Kelola data mahasiswa

3. Halaman kelola kriteria

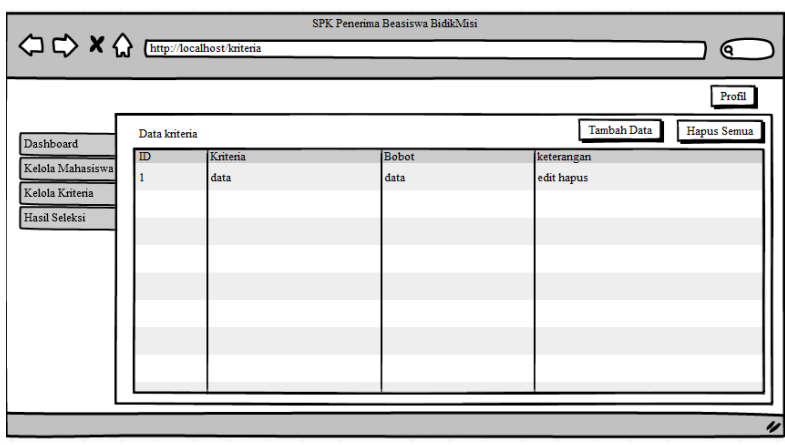

Gambar 10. Halaman Kelola data kriteria

\subsection{Pembuatan Sistem}

Pada sistem pendukung keputusan yang akan dibangun menggunakan bahasa pemrograman PHP dan MySQL sebagai database serta menggunakan framework codeigniter. Sistem yang akan dibangun memiliki beberapa fitur seperti kelola data mahasiswa, kelola data kriteria dan menghitung menggunakan metode weighted product untuk menghasilkan output berupa perangkingan dengan prioritas tertinggi. 


\subsection{Pengujian Sistem}

Untuk melakukan pengujian pada sistem yang akan dibangun menggunakan dua metode pengujian sebagai berikut:

\subsubsection{Metode White Box Testing}

White Box Testing adalah salah satu cara untuk menguji suatu aplikasi atau software dengan cara melihat modul untuk dapat meneliti dan menganalisa kode dari program yang di buat ada yang salah atau tidak [11]. Pada sistem yang akan dibuat pengujian white box dilakukan untuk mengecek hasil perhitungan dari fungsi metode weighted product.

\subsubsection{Metode Black Box Testing}

Black Box Testing atau yang sering dikenal dengan sebutan pengujian fungsional merupakan metode pengujian Perangkat Lunak yang digunakan untuk menguji perangkat lunak tanpa mengetahui struktur internal kode atau program [12]. Pada sistem yang akan dibuat pengujian black box dilakukan untuk mengecek fitur-fitur yang berhubungan dengan pengolahan data.

\section{4. hasil dan PEMBahasan}

\subsection{Implementasi Sistem}

Pada tahap ini akan dilakukan implementasi dari hasil perancangan sistem pada sub bab sebelumnya, beberapa implementasi yang dilakukan sebagai berikut:

\subsubsection{Implementasi Database}

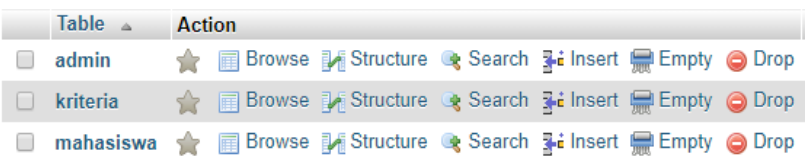

Gambar 11. Implementasi database

Pada sistem pendukung keputusan menggunakan MySQL sebagai penyimpanan data. Database yang dibuat diberi nama dengan spk_bm terdapat 3 tabel antara lain tabel admin, mahasiswa dan kriteria. Dari 3 tabel tersebut terdapat 2 tabel yang saling berelasi untuk digunakan dalam melakukan perhitungan dengan metode weighted product.

\subsubsection{Implementasi Class}

Selanjutnya akan dibahas implementasi class yang digunakan sesuai dengan struktur class framework Codelgniter yakni dengan struktur MVC (Model View Controller) sebagai berikut:

1. Class controller

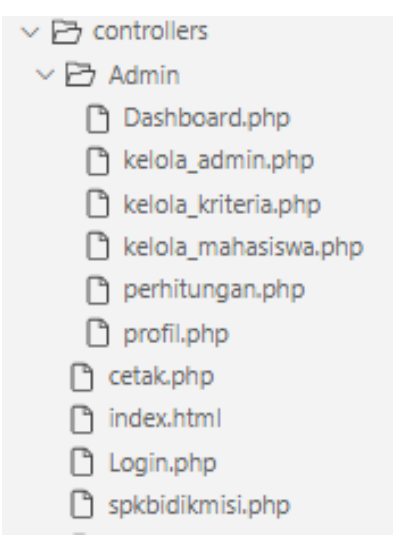

Gambar 12. Class controller pada sistem

Pada class ini berfungsi untuk menghubungkan antara class model dan class view dan yang bertugas dalam untuk mengarahkan halaman-halaman yang dituju. Pada Gambar 12 ditunjukkan class-class controller yang digunakan dalam pembuatan sistem.

2. Class model

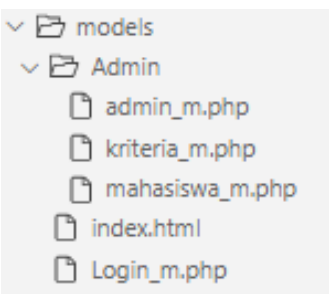

Gambar 13 Class model pada sistem

Pada class ini berfungsi untuk mengolah data seperti menyimpan data, mengedit data , mengambil data dan menghapus data. Pada Gambar 13 ditunjukkan class-class model yang digunakan dalam pembuatan sistem.

3. Class view

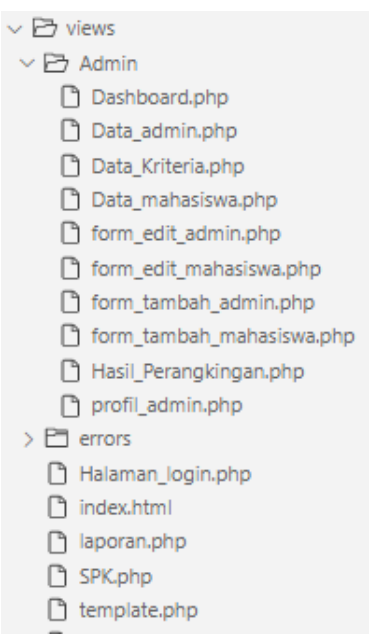

Gambar 14. Class view pada sistem 
Pada class ini berfungsi untuk menampilkan interface pada sistem untuk melakukan interaksi dengan user. Pada Gambar 14 ditunjukkan classclass view yang digunakan dalam pembuatan sistem.

\subsubsection{Implementasi Interface}

Berikut tampilan system yang telah dibuat :

1. Halaman login

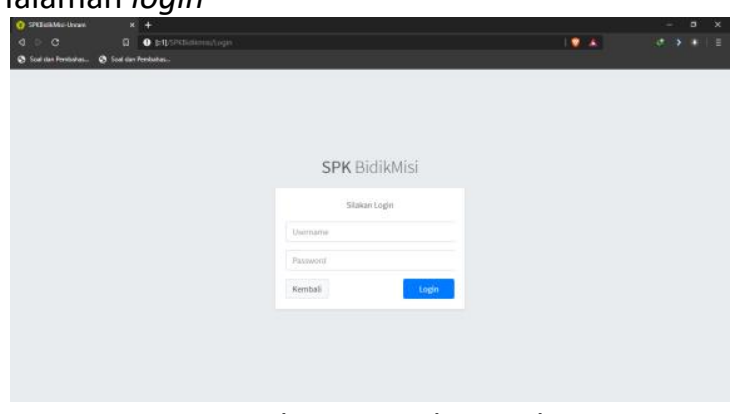

Gambar 15. Halaman login

2. Halaman data mahasiswa

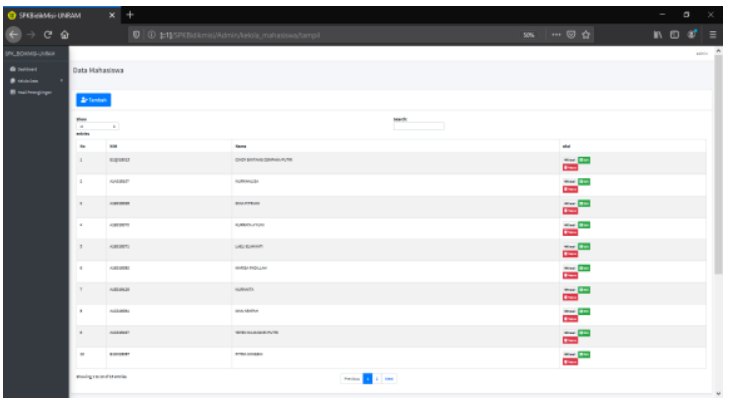

Gambar 16. Halaman data mahasiswa

3. Halaman kriteria dan bobot

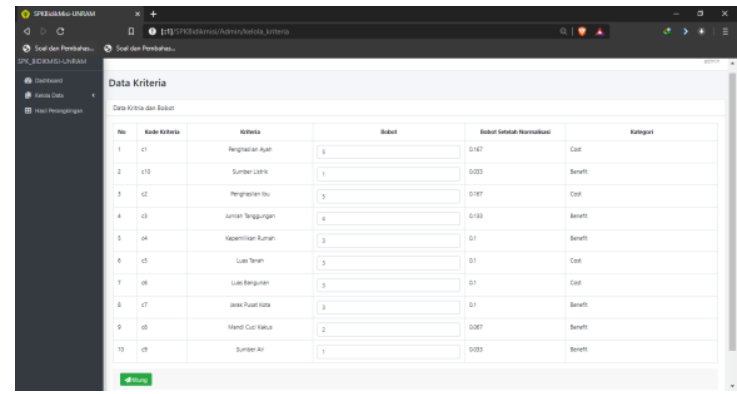

Gambar 17. Halaman kriteria dan bobot

4. Halaman hasil seleksi

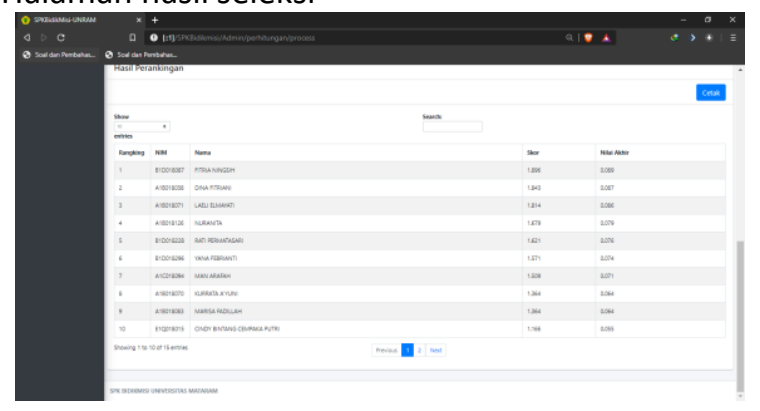

Gambar 18. Halaman hasil seleksi

\subsection{Pengujian Sistem}

Untuk hasil pengujian sistem dilakukan dengan tiga cara yaitu :

\subsubsection{Pengujian Black Box}

Pada pengujian ini dilakukan pengujian fitur-fitur yang terdapat pada sistem yang dilakukan oleh developer sendiri, untuk lebih jelasnya dapat dilihat pada tabel VII di bawah.

TABEL VII. TABEL PENGUJIAN BLACK BOX

\begin{tabular}{|c|c|c|c|c|}
\hline \multirow[t]{2}{*}{ No } & \multirow[t]{2}{*}{ Fungsi } & \multirow{2}{*}{$\begin{array}{l}\text { Hasil yang } \\
\text { diharapkan }\end{array}$} & \multicolumn{2}{|c|}{$\begin{array}{c}\text { Hasil } \\
\text { pengujian }\end{array}$} \\
\hline & & & Sesuai & Tidak \\
\hline 1 & $\begin{array}{l}\text { Login } \\
\text { sebagai } \\
\text { admin }\end{array}$ & $\begin{array}{l}\text { Fungsi login } \\
\text { sebagai } \\
\text { admin sudah } \\
\text { benar }\end{array}$ & 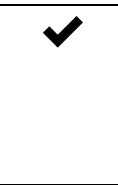 & \\
\hline 2 & $\begin{array}{l}\text { Tambah } \\
\text { data admin }\end{array}$ & $\begin{array}{l}\text { Fungsi } \\
\text { tambah data } \\
\text { admin sudah } \\
\text { benar }\end{array}$ & $\checkmark$ & \\
\hline 3 & $\begin{array}{l}\text { Edit data } \\
\text { admin }\end{array}$ & $\begin{array}{l}\text { Fungsi edit } \\
\text { data admin } \\
\text { sudah benar }\end{array}$ & $\checkmark$ & \\
\hline 4 & $\begin{array}{l}\text { Hapus data } \\
\text { admin }\end{array}$ & $\begin{array}{l}\text { Fungsi hapus } \\
\text { data admin } \\
\text { sudah benar }\end{array}$ & $\checkmark$ & \\
\hline 5 & $\begin{array}{l}\text { Tambah } \\
\text { data } \\
\text { mahasiswa }\end{array}$ & $\begin{array}{l}\text { Fungsi } \\
\text { tambah data } \\
\text { mahasiswa } \\
\text { sudah benar }\end{array}$ & $\checkmark$ & \\
\hline 6 & $\begin{array}{l}\text { Edit data } \\
\text { mahasiswa }\end{array}$ & $\begin{array}{l}\text { Fungsi edit } \\
\text { data } \\
\text { mahasiswa } \\
\text { sudah benar }\end{array}$ & $\checkmark$ & \\
\hline 7 & $\begin{array}{l}\text { Hapus data } \\
\text { mahasiswa }\end{array}$ & $\begin{array}{l}\text { Fungsi hapus } \\
\text { data } \\
\text { mahasiswa } \\
\text { sudah benar }\end{array}$ & $\checkmark$ & \\
\hline 8 & $\begin{array}{l}\text { Lihat detail } \\
\text { data } \\
\text { mahasiswa }\end{array}$ & $\begin{array}{l}\text { Fungsi lihat } \\
\text { detail data } \\
\text { mahasiswa } \\
\text { sudah benar }\end{array}$ & $V$ & \\
\hline 9 & $\begin{array}{l}\text { Edit bobot } \\
\text { kriteria }\end{array}$ & $\begin{array}{l}\text { Fungsi edit } \\
\text { bobot kriteria } \\
\text { sudah benar }\end{array}$ & $\checkmark$ & \\
\hline 10 & $\begin{array}{l}\text { Cetak data } \\
\text { hasil } \\
\text { perankingan }\end{array}$ & $\begin{array}{ll}\text { Fungsi } & \text { cetak } \\
\text { data } & \text { hasil }\end{array}$ & $V$ & \\
\hline
\end{tabular}




\begin{tabular}{|l|l|l|l|l|}
\hline & $\begin{array}{l}\text { perangkingan } \\
\text { sudah benar }\end{array}$ & & \\
\hline
\end{tabular}

\subsubsection{Pengujian White Box}

Pada pengujian ini dilakukan pengecekan langkah-langkah metode yang digunakan pada sistem yaitu metode weighted product dalam melakukan perhitungan.

TABEL VIII. TABEL PENGUJIAN WHITE BOX

\begin{tabular}{|c|c|c|c|}
\hline Path & Kasus Uji & Hasil Uji & Keterangan \\
\hline 1 & $\begin{array}{l}\text { Menginputkan } \\
\text { bobot setiap } \\
\text { kriteria }\end{array}$ & $\begin{array}{l}\text {-Data } \\
\text { berhasil } \\
\text { tersimpan } \\
\text {-Mendapat } \\
\text { hasil } \\
\text { perhitungan }\end{array}$ & $\begin{array}{l}\text { [ } \vee \text { ] Alur } \\
\text { terlewati } \\
\text { [ ] Alur } \\
\text { tidak } \\
\text { terlewati }\end{array}$ \\
\hline 2 & $\begin{array}{l}\text { Menghitung } \\
\text { nilai vektor s } \\
\text { dan vektor v }\end{array}$ & $\begin{array}{l}\text { Berhasil } \\
\text { menghitung } \\
\text { vektor s dan } \\
\text { vektor v }\end{array}$ & $\begin{array}{l}\text { [ } \vee \text { ] Alur } \\
\text { terlewati } \\
\text { [ ] Alur } \\
\text { tidak } \\
\text { terlewati }\end{array}$ \\
\hline 3 & $\begin{array}{l}\text { Mencari nilai } \\
\text { bobot } \\
\text { normalisasi } \\
\text { sesuai dengn } \\
\text { id kriteria }\end{array}$ & $\begin{array}{l}\text { Berhasil } \\
\text { mendapat } \\
\text { nilai bobot } \\
\text { normalisasi } \\
\text { sesuai } \\
\text { dengn id } \\
\text { kriteria }\end{array}$ & $\begin{array}{l}\text { [ } \vee \text { ] Alur } \\
\text { terlewati } \\
\text { [ ] Alur } \\
\text { tidak } \\
\text { terlewati }\end{array}$ \\
\hline
\end{tabular}

\subsubsection{Pengujian Most Opinion Score (MOS)}

Pengujian ini dilakukan dengan kuisioner untuk mengetahui kinerja dan kualitas sistem dari sisi pengguna.

Pengujian dengan metode Mean Opinion Score Sistem Pendukung Keputusan Penerima Beasiswa Bidikmisi Universitas Mataram. Berikut ini perhitungan yang sudah dilakukan pada lima responden yaitu pegawai Subbagian Kesejahteraan Mahasiswa Universitas Mataram dapat dilihat pada Tabel IX.
TABEL IX. HASIL PERHITUNGAN MOS PEGAWAI

\begin{tabular}{|c|c|c|c|c|c|c|c|}
\hline \multirow{2}{*}{ No } & \multirow{2}{*}{ Pertnyaan } & \multicolumn{5}{|c|}{ Penilaian } & \multirow{2}{*}{ Mean } \\
\hline & & 1 & 2 & 3 & 4 & 5 & \\
\hline 1 & Pertanyaan 1 & & & & 3 & 2 & 4,4 \\
\hline 2 & Pertanyaan 2 & & & & 1 & 4 & 4,8 \\
\hline 3 & Pertanyaan 3 & & & & 4 & 1 & 4,2 \\
\hline 4 & Pertanyaan 4 & & & & 3 & 2 & 4,4 \\
\hline 5 & Pertanyaan 5 & & & & 2 & 3 & 4,6 \\
\hline & Sub Total & & & & 13 & 13 & 22,4 \\
\hline \multicolumn{7}{|c|}{ MOS (Mean Opinion Score) } & 4,48 \\
\hline
\end{tabular}

Berdasarkan hasil pengujian MOS yang dilakukan oleh lima pegawai Subbagian Kesejahteraan Mahasiswa Universitas Mataram, para responden telah memberikan penilaian pada setiap pertanyaan. Rincian penilaian MOS dapat dilihat pada Tabel 4.6. Pengujian yang dilakukan pada pegawai Subbagian Kesejahteraan Mahasiswa Universitas Mataram dengan MOS $=4.48$ atau kategori Very Good(Sangat Bagus) [13].

Berikut ini perhitungan yang sudah dilakukan pada 30 responden yaitu mahasiswa Universitas Mataram yang diambil secara acak dengan kusioner online dapat dilihat pada Tabel X.

TABEL X. HASIL PERHITUNGAN MOS MAHASISWA

\begin{tabular}{|c|c|c|c|c|c|c|c|}
\hline \multirow{2}{*}{ No } & \multirow{2}{*}{ Pertnyaan } & \multicolumn{5}{|c|}{ Penilaian } & \multirow[t]{2}{*}{ Mean } \\
\hline & & 1 & 2 & 3 & 4 & 5 & \\
\hline 1 & Pertanyaan 1 & & & 3 & 19 & 8 & 4,17 \\
\hline 2 & Pertanyaan 2 & & & 3 & 17 & 10 & 4,23 \\
\hline 3 & Pertanyaan 3 & & & 4 & 18 & 8 & 4,13 \\
\hline & Sub Total & & & 10 & 54 & 26 & 12,53 \\
\hline \multicolumn{7}{|c|}{ MOS (Mean Opinion Score) } & 4,17 \\
\hline
\end{tabular}

Berdasarkan hasil pengujian MOS yang dilakukan oleh 30 mahasiswa Universitas Mataram yang diambil secara acak, para responden telah memberikan penilaian pada setiap pertanyaan. Rincian penilaian MOS dapat dilihat pada Tabel 4.7. Pengujian yang dilakukan pada pegawai mahasiswa Universitas Mataram dengan MOS $=4.17$ atau kategori Good (Bagus) [13].

\section{Kesimpulan dan Saran}

\subsection{Kesimpulan}

Berikut kesimpulan yang didapat dari sistem pendukung keputusan yang telah dibuat dengan metode weighted product :

1. Sistem pendukung keputusan yang telah dibuat sudah sesuai dengan perancangan serta berjalan dengan baik dan benar.

2. Hasil yang didapat sistem dengan hasil perhitungan manual dengan Microsoft excel sudah sesuai dan 
menghasilkan nilai akhir yang sama dengan tingkat akurasi $100 \%$.

3. Sistem pendukung keputusan dapat mempermudah dalam pengolahan data dalam jumlah besar serta dapat meminimaisir waktu penentuan penerima beasiswa bidikimisi Universitas Mataram tahun 2018.

4. Hasil kusioner dari sisi admin atau pegawai mendapat nilai MOS sebesar 4,48 atau kategori Very Good (Sangat Bagus) sedangkan dari sisi mahasiswa mendapat nilai MOS sebesar 4,17 atau kategori Good ( Bagus ).

\subsection{Saran}

Berikut saran untuk sistem pendukung keputusan yang telah dibuat agar bisa dikembangkan pada peneltian selanjutnya :

1. Membuat tampilan atau user interface yang lebih menarik.

2. Masalah kriteria mahasiswa yang masih statis dalam penambahan, diharapakan pada penelitian selanjutnya bisa bersifat dinamis.

3. Menggunakan metode sistem pendukung keputusan yang lain.

\section{DAFTAR PUSTAKA}

[1] R. Fauzan, Y. Indrasary, and N. Muthia, "Sistem Pendukung Keputusan Penerimaan Beasiswa Bidik Misi di POLIBAN Dengan Metode SAW Berbasis Web," JOIN (Jurnal Online Inform., vol. 2, no. 2, pp. 79-83, 2017, doi: 10.15575/join.v2i2.101.

[2] D. Puspitasari, M. Mentari, and F. A. Gunawan, "Sistem Pendukung Keputusan Penentuan Penerimaan Mahasiswa Baru Jalur Bidikmisi Menggunakan Metode Topsis (Studi Kasus: Politeknik Negeri Malang)," J. Infromatika Polinema, vol. 4, pp. 63-70, 2017.

[3] D. Kusumawati, "Penentuan Penerima Beasiswa Menggunakan Simple Additive Weighting Dan Weighted Product," J. Elektron. Sistim Inf. Dan Komput., vol. 1, no. 1, pp. 1-4, 2015.

[4] P. Oktavia, "Sistem Pendukung Keputusan Seleksi Penerima Beasiswa dengan Metode Weighted Product pada SMP Negeri 1 Parung Berbasis Web," J. Inform. Univ. Pamulang, vol.
3, no. 2, p. 80, 2018, doi: 10.32493/informatika.v3i2.1432.

[5] Nurjaya, "Perbandingan Metode SAW Dengan Metode WP Pada Sistem Seleksi Karyawan Tetap," 2017.

[6] R. R. Ayu Septiana Sari, Jumadil Nangi, “Penerapan Metode Promethee Dalam Sistem Penunjang Keputusan Penentuan Penerima Beasiswa Bidik Misi Universitas Halu Oleo," Bianglala Inform., vol. 3, no. 1, pp. 229-236, 2015.

[7] M. Muslihudin, R. F. Andriyanti, and S. Mukodimah, "Implementasi Metode Weighted Product Menentukan Beasiswa Bidik Misi Stmik Pringsewu," Jatisi, vol. 4, no. 2, pp. 156-163, 2018.

[8] H. K.S, H. S, and R. Warodyo, Fuzzy MultiAttribute Decision Making(Fuzzy MADM). Yogyakarta: Graha IImu, 2006.

[9] M. Riadi, "Pengertian Sistem Pendukung Keputusan," Kajianpustaka.com, 2013. [Online]. Available: https://www.kajianpustaka.com/2013/09/sist em-pendukung-keputusan-spk.html.

[Accessed: 02-Oct-2019].

[10] Pengajarku, "Analisis Sistem: Pengertian, Tujuan, Fungsi, Tahapan dan Contohnya," pengajar.co.id, 2019. [Online]. Available: https://pengajar.co.id/analisis-sistempengertian-tujuan-fungsi-tahapan-dancontohnya/. [Accessed: 08-Oct-2019].

[11] Dosenpendidikan, "Pegujian dan Pengertian White Box Testing," dosenpendidikan.co.id, 2019. [Online]. Available: https://www.dosenpendidikan.co.id/pegujiandan-pengertian-white-box-testing/. [Accessed: 17-Oct-2019].

[12] P. Kurniawati, "Pengujian Sistem," medium.com, 2018. [Online]. Available: https://medium.com/skyshidigital/pengujiansistem-52940ee98c77. [Accessed: 17-Oct2019].

[13] R. Fitriyanti, Lindawati, and A. Aryanti, "Studi Literatur Mean Opinion Score Menggunakan Moving Picture Quality Metrics (MPQM) Di Jaringan LTE," Semin. Nas. Inov. dan Apl. Teknol. di Ind. 2018 Tema A - Penelit., vol. 4, no. 2, pp. 10-14, 2018. 